\title{
PEMBELAJARAN MOBILE LEARNING UNTUK SISWA SMA
}

\author{
Esterika Geofany Pangalo \\ Teknologi Pendidikan, Fakultas Ilmu Pendidikan, Universitas Negeri Malang \\ esterika.geofany.1801216@students.um.ac.id
}

\begin{abstract}
Abstrak: Jurnal ini bertujuan untuk mengetahui pemanfaatan mobile learning dalam proses pembelajaran dalam upaya untuk membentuk pembelajaran yang semakin signifikan dan berkualitas. Penggunaan media dalam pembelajaran menambah poin untuk membuat pegangan pembelajaran berhasil dan efektif sehingga kualitas pengajaran dapat ditingkatkan. Kedekatan pembelajaran Mobile Learning adalah perencanaan sebagai pelengkap pembelajaran yang ada dan memberikan celah bagi siswa untuk mempelajari kembali bahan yang tidak cocok di mana pun dan kapan pun. Ini tentu saja dapat memberikan keterlibatan yang beragam dalam persiapan pembelajaran bagi siswa.
\end{abstract}

Kata kunci: Pembelajaran, Mobile Learning, Siswa SMA.

Abstract: This journal aims to determine the use of mobile learning in the learning process in an effort to shape increasingly significant and quality learning. The use of media in learning adds points to make the handle of learning successful and effective so that the quality of teaching can be improved. Proximity of learning Mobile Learning is planning as a complement to existing learning and provides a loophole for students to relearn material that is not suitable anywhere and anytime. This of course can provide diverse involvement in the preparation of learning for students.

Keywords: Learning, Mobile Learning, High School Students. 


\section{PENDAHULUAN}

Pembelajaran merupakan suatu sistem atau proses membelajarkan pembelajar yang direncanakan, dilaksanakan dan dievaluasi secara sistematis agar pembelajar dapat mencapai tujuantujuan pembelajaran secara efektif dan efesien (Komalasari, 2013). Proses belajar mengajar merupakan proses pendekatan komunikatif antara guru dan peserta didik yang datang dari faktor internal (diri sendiri) maupun foktor eksternal (lingkungan). Dalam sebuah proses komunikasi terkadang mengalami hambatan sehingga dibutuhkan perantara yang berupa media pembelajaran yang dapat menjembatani komunikasi antara guru dan peserta didik.

Tugas pendidik yang paling utama adalah menciptakan lingkungan yang menunjang terjadinya perubahan perilaku bagi peserta didik. Perkembangan yang cepat menuntut guru untuk meningkatkan pembelajaran, salah satunya adalah media pembelajaran. Inovasi media pembelajaran saat ini di tuntut untuk dapat mengikuti perkembangan ilmu pengetahuan dan teknologi yang sedang berkembang. Perkembangan teknologi mobile device yangberkembang secara pesat mampu memberikan peluang dalam pengembangan media mobile learning.

Salah satu kegunaan media pembelajaran dalam proses belajar mengajar dapat membangkitkan keinginan dan minat yang baru, membangkitkan motivasi dan rangsangan kegiatan belajar dan membawa pengaruh-pengaruh psikologi terhadap siswa.Media pembelajaran juga dapat membantu siswa meningkatkan pemahaman, menyajikan data dengan menarik dan terpercaya, memudahkan penafsiran data, dan memadatkan informasi. Namun media pembelajaran harus dapat memberikan pengalaman yang menyenangkan dan memenuhi kebutuhan perorangan siswa.

Penggunaan media pembelajaran yang menarik akan meningkatkan motivasi dan minat siswa untuk belajar yang pada akhirnya akan membuat siswa berhasil memahami materi yang diberikan(Setyadi \& Qohar, 2017) 
.Penggunaan mobile learning sebagai media pembelajaran ini dapat membantu peserta didik dalam mempelajari materi secara mudah. Pengembangan mobile learning ini ditunjukkan untuk dapat dioperasikan pada smartphone. Penerapan teknologi informasi dan komunikasi dalam pembelajaran sudah menjadi suatu keharusan, karena penerapan teknologi informasi dan komunikasi merupakan salah satu indikator keberhasilan dalam sebuah pembelajaran .

Selain itu dikehidupan masa kini menuntut siswa untuk dapat menguasai berbagai keterampilan salah satunya keterampilan berpikir kritis .Siswa dapat dikatakan mampu berpikir secara kritis ketika dapat berbicara mengunakan alasan yang tepat, baik secara nalar dan sistematis untuk memecahkan suatu masalah.Berpikir kritis adalah sebuah proses dimana seseorang mencoba untuk menjawab secara rasional pertanyaan-pertanyaan yang tidak dapat dijawab secara mudah dan dimana semua informasi yang relevan tidak tersedia (Inch, 1989). Kemampuan berpikir kritis pada siswa sendiri dapat dilatih dengan menggunakan beradu argumen atau sekedar menjawab pertanyaan (MIFTAH RAHMAWATI, 2017) .Mobile learning dapat diartikan sebagai suatu Fasilitas yang memberikan informasi .elektronik secara umum kepada pembelajar dan content yang edukasional yang membantu mencapai pengetahuan tanpa mempersalahkan lokasi dan waktu (Arifpurnamayana, 2012). Mobile learning merupakan bagian dari e-Learning yang lebih mengarah dalam memanfaatkan kecanggihan telepon genggam. Mobile learning menyediakan materi pelajaran yang dapat diakses dimana saja dan kapan saja dengan tampilan yang menarik (Fatmawati, 2015).

Penggunaan mobile learning akan meningkatkan motivasi belajar siswa dan perhatian siswa dalam kegiatan belajar. Selain itu, dibandingkan dengan sistem belajar mengajar yang tradisional,mobile learning memungkinkan terjadinya lebih banyak kesempatan untuk kolaborasi secara langsung dan berinteraksi secara informal di antara siswa (Fatmawati, 2015).Mobile 
learning (M-learning) adalah media pembelajaran yang memanfaatkan sebuah teknologi informasi dan komunikasi (Setiawati, Kartika, \& Purwanto, 2012).

Klien pembelajaran yang serba guna dapat mencapai substansi instruktif tanpa terikat oleh keberadaan. Kedekatan M-learning akan tanpa ragu tidak memiliki pilihan untuk menggantikan elearning (elektronik menyadari) yang khas belum lagi belajar dengan dekat dan pribadi di kelas. Kedekatan Mlearning diusulkan untuk melengkapi pembelajaran yang ada dan memberikan kesempatan kepada siswa untuk mempelajari kembali materi yang tidak cocok di mana pun dan kapan pun. Ini tentunya dapat memberikan keterlibatan alternatif dengan prosedur pembelajaran untuk siswa. Ini akan membangun penghargaan untuk materi pembelajaran, membuat pembelajaran meyakinkan, dan memberdayakan inspirasi siswa untuk pembelajaran yang mengakar dalam (pembelajaran jangka panjang).
Berbagai

penelitian menunjukkan penggunaan mobile learning dapat melatih keterampilan berpikir kritis siswa .Pengembangan mobile learning sebagai media pembelajaran telah dilakukan oleh beberapa peneliti, diantaranya oleh (Purbasari, Kahfi, \& Yunus, 2013) dan (Kusuma, 2016) yang mengembangkan mobile learning berbasis android. Hasil pengembangan yang dilakukan oleh kedua peneliti tersebut menunjukkan bahwa media yang dikembangkan lebih cenderung memfokuskan pada materi ajarnya saja. Mobile learning yang dikembangkan belum difokuskan sebagai sarana berlatih mengerjakan soal yang dapat memberikan berbagai jenis soal yang bervariasi dan menantang.

\section{HASIL TELAAH}

Produk yang direview adalah media pembelajaran berbasis mobile learning yang diterapkan pada kegiatan pembelajaran di dalam kelas maupun di luar kelas. Media pembelajaran ini diharapkan dapat mempermudah pendidik maupun siswa dalam melakukan 
pembelajaran. Siswa diharapkan dapat belajar secara mendiri di mana pun dan kapan pun sehingga dapat meningkatkan kemampuan berpikir kritisnya (Purnama, 2017).Sehingga media pembelajaran yang dikembangkan dapat dijalankan sesuai dengan kegunaannya.

Media pembelajaran ini diingat untuk kelas media pembelajaran yang bergantung pada pembelajaran portabel. Ini sesuai dengan makna pembelajaran serba guna yang diungkapkan oleh O'Malley (2003: 6), untuk secara spesifik menemukan bahwa (siswa) tidak hanya tetap berada di satu tempat atau latihan pembelajaran yang terjadi ketika siswa menggunakan gadget inovasi portable.Kebanyakan siswa SMA/MA sudah setiap hari memakai smartphone. Smartphone yang beredar di pasaran ada yang sangat populer yaitu Apple dan Android. Smartphone yang menjadi tren masa kini dan perkembangannya sangat pesat adalah Android, sehingga pengembangan mobile learning dalam Android ini sangat menjanjikan. Penggunaan media mobile learning sangat membantu dalam penyampaian materi pelajaran. Materi yang diajarkan di SMA/MA sangat banyak dan alokasi waktu yang diberikan dalam proses pembelajaran di sekolah sangat terbatas. Keterbatasan alokasi waktu ini menyebabkan guru terkadang hanya mengutamakan penyelesaian materi pelajaran dan kurang memberi kesempatan siswa untuk berlatih mengerjakan soal.

Kurangnya siswa dalam berlatih soal dapat mengakibatkan ketidakmampuan terhadap materi dan konsep juga kurang optimal. Perangkat mobile yang digunakan dalam mobile learning antara lain : telepon genggam/smarthphone, laptop, dan PC. Karakteristik perangkat mobile ini memiliki tingkat fleksibilitas dan portabilitas yang sanggat tinggi sehingga dapat memungkinkan siswa untuk dapat mengakses materi, petunjuk dan informasi yang berkaitan dengan pembelajaran kapan saja dan dimana saja dirinya berada. Penggunaan handphone dalam bidang pendidikan di Indonesia, khususnya untuk pembelajaran peserta didik secara 
mandiri masih sangat sedikit digunakan, padahal setiap hari peserta didik tidak lepas dari handphone.

$$
\text { Pengembangan media }
$$

pembelajaran mobile learning mampu menjadi salah satu alternatif media pembelajaran mandiri yang lebih menarik, lebih mudah, lebih hemat dan dapat digunakan oleh pengguna/peserta didik belajar dimana pun dan kapan pun diperlukan. Salah satu yang menjadi pertimbangan dalam mengembangkan handphone menjadi media pembelajaran mobile learning adalah basis sistem operasi yang digunakan. Sistem operasi merupakan penghubung antara aplikasi dengan hardware sehingga pengguna dapat menjalankan fungsi-fungsi tertentu.

Sistem operasi pada handphone yang digunakan oleh siswa di SMA berbasis android, selebihnya adalah iphone dll. Android adalah kerangka kerja ponsel yang memuaskan. Kerangka kerja Android yang mendukung kemajuan aplikasi dan peralatan menyampaikan batas pada peralatan yang memanfaatkan kerangka kerja Android diandalkan untuk menciptakan delegasi media pembelajaran serbaguna. Media yang dihasilkan tidak hanya monoton dengan teks saja, tetapi juga memuat unsur-unsur multimedia audio/visual bahkan animasi yang memudahkan siswa dalam memahami materi.

Aplikasi yang dikembangkan pada jurnal ini tidak dapat dijalankan pada semua jenis perangkat mobile mengingat aplikasi ini hanya dapat dijalankan pada perangkat mobile berbasis Android. Oleh karena itu, diharapkan dapat dilakukan pembaharuan aplikasi sejenis yang dapat dijalankan pada perangkat dengan sistem operasi yang berbedabeda dan pada materi yang lebih beragam pula. Dengan adanya pembaharuan pada aplikasi pembelajaran pada perangkat mobile diharapkan dapat meningkatkan manfaat perangkat mobile dalam bidang pendidikan dan meningkatkan semangat belajar siswa. Selain itu, adanya aplikasi-aplikasi seperti ini dapat memberikan dan menambah pengalaman belajar yang menarik dan baru bagi siswa.

Media pembelajaran yang dibuat memiliki beberapa hal yang menarik dan merugikan. Media 
pembelajaran kehebatan dibuat, yang dapat bekerja pada gadget yang bergantung pada Android dan Windows; memperkenalkan bahan pemisahan dalam ruang tiga dimensi dengan cara yang menarik dan langsung; menyajikan contoh masalah yang berfluktuasi dengan perubahan derajat masalah; pengenalan materi dilengkapi dengan gambar dan kegiatan untuk membantu siswa memahami materi. Selain keadaan yang menguntungkan yang dirujuk sebelumnya, media pembelajaran juga mengalami kekurangan. Adapun kelemahan media pembelajaran mobile learning antara lain tidak dapat dioperasikan pada perangkat mobile dengan sistem operasi selain Android,interaktivitas media masih kurang, akan tertinggal jika sistemnya tidak dipernaharui secara berkala.

Kecepatan prosesor pada gadget meningkat dan lebih baik, sementara batas memori, terutama memori luar, saat ini semakin besar dan lebih murah.Adapun beberapa kekurangan Mobile learning dalam (Tamimuddin, 2007; Sarrab, 2012). Antara lain : Kemampuan prosesor,
Kapasitas memori, Layar tampilan, Catu daya ,Perangkat I/O, Perbedaan user interface (UI) yang menyediakan interaksi antara manusia dengan komputer dengan teknologi yang baru dan belum pernah dikembangkan sebelumnya, Platform seluler yang berbeda seperti iOS, Android, dan Windows. Pembuat perangkat keras yang berbeda untuk platform seperti HTC, Google, Samsung, Apple dan lain-lain.

Manfaat penggunaan mobile learning adapun yang menjadi fungsi atau manfaat mobile learning dalam pembelajaran adalah sebagaimana yang kemukakan oleh (Miftah,(Nugroho, 2014) 2010) dalam tulisan nya yang berjudul implementasi teori belajar dan desain sistem pembelajaran mobile learning, bahwa terdapat tiga fungsi utama penggunaan mobile learning adalah sebagai: (1) Mobile learning sebagai suplement dapat diartikan bahwa terdapat kebebasan bagi siswa untuk memilih dan memanfaatkan mobile dalam mengakses materimateri pembelajaran ataupun dalam penggunaan nya sebagai media pembelajaran.(2) Mobile learning 
dapat dikatakan sebagai pelengkap karena dapat digunakan sebagai alat evaluasi, pemberian pengayaan serta, penguatan dan dapat digunakan untuk mengulang kembali (recalling) pembelajaran yang telah dilakukan meski tanpa bantuan dan pendampingan dari guru atau tutor.

(3) Pembelajaran bergerak sebagai pengganti dapat menyiratkan bahwa siswa dapat diberi kesempatan dalam memilih model pembelajaran yang ideal. Apakah model pembelajaran yang ideal adalah belajar dengan (1) Menggunakan model pembelajaran reguler, (2) Memadukan model dengan menggabungkan model pembelajaran biasa dengan inovasi atau, (3). Benar-benar menggunakan model pembelajaran yang menggunakan inovasi.

Kapasitas lain dari pemanfaatan pembelajaran serbaguna dalam pembelajaran juga diperkenalkan oleh (Baker, Krull, \& Mallinson, 2005)yang dalam bahasa disinggung sebagai efek dalam pemanfaatan inovasi sel, untuk menjadi spesifik: 1) Portabilitas Mobile (nirkabel) memiliki kemampuan bergerak bekerja karena memungkinkan siswa untuk melakukan pembelajaran mandiri kapan saja dan di mana saja dengan memperoleh data atau mengambil kursus melalui ponsel mereka sebagai kursus berbayar atau sebagai kursus gratis.

2) Kolaborasi Siswa dapat berkonsentrasi bersama atau bekerja sama dengan siapa pun dengan menggunakan organisasi antarpribadi, misalnya, Facebook, WhatsApp, Twitter, dan lainnya yang dapat memberdayakan siswa pengganti untuk membuat pertemuan atau pertemuan yang dapat mereka gunakan sebagai tempat untuk berbicara atau berbagi data yang dapat memasukkan dan meningkatkan wawasan mereka.

3) Motivasi Pemanfaatan portabel dalam pembelajaran dapat membantu meningkatkan inspirasi dan antusiasme siswa untuk mengikuti mata pelajaran yang dipertimbangkan mengingat fakta bahwa siswa dapat sepenuhnya terkait dengan prosedur pembelajaran.

Adapun manfaat dari penggunaan mobile dalam pembelajaran sebagai mana yang di 
kemukan oleh (Woodille, 2011) keuntungan utama dalam penggunaan mobile device dalam pembelajaran dapat dijabarkan sebagai berikut: Pertama,Portabilitas. Kedua, Kapan saja dan conect dimana saja. Ketiga, Akses yang fleksible dan secara tepat mengases pada sumber-sumber elearning . Keempat, Komunikasi yang cepat. Kelima, Pemberdayaan dan keterlibatan peserta didik, terutama yang berada di masyarakat luas. Enam,Pengalaman belajar aktif.

Android memiliki empat karakteristik sebagai berikut: (http://liveintranet.blogspot.com/)

Pertama,Terbuka.Android di ciptakan untuk benar-benar terbuka sehingga sebuah kita dapat membuat panggilan, mengirim pesan teks, menggunakan kamera dan lain-lain. Android adalah mesin virtual yang secara eksplisit dimaksudkan untuk merampingkan aset dan peralatan memori yang terdapat dalam gadget. Android adalah open source, dapat diperpanjang untuk memasukkan kemajuan baru yang dikembangkan lebih lanjut ketika inovasi muncul. Tahap ini akan terus dibuat untuk membuat aplikasi serbaguna yang imajinatif. Kedua, semua aplikasi dibuat setara. Android tidak berpengaruh pada aplikasi prinsip dari aplikasi telepon dan orang luar.

Semua aplikasi dapat berfungsi untuk memiliki akses yang setara ke kapasitas telepon untuk menawarkan klien dengan jenis bantuan dan aplikasi yang luas. Ketiga, Memecah batas pada aplikasi Android memisahkan penghalang untuk membangun aplikasi baru dan inventif. Misalnya, desainer dapat menggabungkan data yang didapat dari web dengan informasi di ponsel seseorang, misalnya, kontak klien, jadwal, atau area daratan.

Keempat, kemajuan penggunaan yang cepat dan sederhana Android memberi klien dengan akses yang sangat luas untuk memanfaatkan aplikasi yang menunjukkan tanda-tanda perbaikan. Android memiliki banyak instrumen yang dapat digunakan untuk membantu insinyur dengan meningkatkan keuntungan ketika membangun aplikasi yang dibuat. Memanfaatkan ponsel dan tablet, memberi siswa memiliki akses mudah 
ke informasi. Jelas ini dapat meningkatkan semesta pelatihan.

Pembelajaran yang serba guna dapat mendorong siswa-siswa sederhana untuk memberikan semua lebih transparan ketika mereka berada di kelas. Pendidik juga dapat menggunakan ponsel untuk berkomunikasi dengan siswa yang membutuhkan pertimbangan luar biasa. Konsekuensi dari penelitian dalam menciptakan aplikasi pembelajaran serbaguna adalah mempelajari item aplikasi media dan aset pembelajaran elektif yang dapat dijalankan di ponsel dengan kerangka kerja Android. Kedudukan aplikasi dalam pembelajaran adalah sebagai suplemen. Suplemen yang dimaksud adalah penunjang pembelajaran dimana waktu dan tempat penggunaannya tidak harus di dalam kelas melainkan bisa di luar jam pembelajaran. Aplikasi sebagai suplemen dimaksudkan agar siswa dapat bermain dan belajar secara mandiri pada waktu luang mereka, mengingat waktu belajar di sekolah sangat terbatas.

Pengertian ini senada dengan yang dikemukakan oleh (Kim,
Rueckert, Kim, \& Seo, 2013)mobile learning dapat digunakan oleh pendidik untuk menyampaikan materi pembelajaran secara fleksibel dimanapun dan kapanpun. Sementara itu (C, L, G, 2013)mendefinisikan Mobile Learning adalah jenis pembelajaran yang memberikan konten pendidikan dan materi pendukung pembelajaran melalui perangkat komunikasi nirkabel.. Kerangka kerja m-learning ini menggunakan portabilitas ponsel, misalnya, ponsel dan PDA, untuk memberikan kapasitas pembelajaran yang seharusnya dimungkinkan di mana saja dan kapan saja. Pembelajaran serba guna tidak dapat menggantikan kelas-kelas adat namun dapat digunakan sebagai pelengkap dalam prosedur pembelajaran di ruang kelas dan perguruan tinggi.

Mobile Learning memungkinkan penggabungan dan koneksi antara teknologi dan pendidikan. Pemahaman termasuk bepergian, kelembagaan, rumah, anak-anak dan klien dewasa dan situasi belajar yang berbeda termasuk gratis, ruang sekolah, pengaturan, 
berbasis web, keliling, pemisahan, komunitarian, non-arus, dan serentak akan membangkitkan antusiasme zaman pembelajaran pemisahan lainnya ( Pembelajaran Bergerak). Buku harian ini telah berbicara tentang fondasi Pembelajaran Bergerak dan bagaimana ia cenderung digunakan untuk meningkatkan kerangka pembelajaran umum.Jurnal ini juga memberikan sorotan tentang manfaat dan tantangan Mobile Learning di masa depan di lingkungan pendidikan kita. Akhirnya, peserta didik, instruktur, siswa, dan guru kami harus siap untuk pembelajaran dan pelatihan generasi berikutnya.

Pelajaran termasuk pelayaran, kelembagaan, rumah, anak-anak dan pelanggan dewasa dan keadaan belajar yang berbeda termasuk gratis, ruang sekolah, mengatur, elektronik, nomad, divisi, komunitarian, nonconcurrent, dan sinkron akan mencampur energi waktu pembelajaran detasemen lain (Pembelajaran Bergerak) . Jurnal ini telah membahas pembentukan Pembelajaran Seluler dan bagaimana secara umum akan digunakan untuk meningkatkan kerangka pembelajaran umum . Baik guru dan siswa membutuhkan sistem yang tepat dan praktis untuk berinteraksi satu sama lain dan memfasilitasi sistem pengajaran. Sistem Mobile learning bukan untuk menggantikan ruang kelas tradisional tetapi mereka dapat digunakan untuk melengkapi proses pembelajaran di sekolah dan universitas yang ada.

Perangkat komputasi dan komunikasi seperti ponsel pintar, laptop, dan PDA dengan koneksi ke jaringan nirkabel memfasilitasi Mobile Learning. Mobile Learning memungkinkan pendidik, pelajar dan guru untuk melampaui ruang sekolah tradisional (ruang kelas, ruang tutorial, laboratorium dan teater kuliah); Ruang sekolah, komputer jinjing, dan perangkat komunikasi memberi instruktur dan pelajar peningkatan fleksibilitas dan menawarkan peluang interaksi baru.

Manfaat pembelajaran mobile learning yang pertama, Akses kapan saja ke konten.Kedua,Di mana saja akses ke konten. Ketiga, Mendukung pembelajaran jarak jauh.Keempat, 
Dapat meningkatkan pembelajaran yang berpusat pada siswa.

Kelima, Sangat bagus untuk pelatihan yang tepat waktu atau peninjauan konten.Keenam, Dapat digunakan secara lebih efektif untuk orang yang memiliki kemampuan berbeda. Ketujuh, Mendukung diferensiasi kebutuhan belajar siswa dan pembelajaran yang dipersonalisasi.Kedelapan, Dapat meningkatkan interaksi antara dan di antara siswa, peserta didik dan instruktur.Kesembilan, Mengurangi hambatan budaya dan komunikasi antara dosen dan mahasiswa dengan menggunakan saluran komunikasi yang disukai siswa.

Mobile learning adalah perpanjangan alami dari E-learning. Ini memiliki potensi untuk memperpanjang kapan, di mana dan bagaimana siswa belajar dan melakukan dalam semua aspek kehidupan mereka. Salah satu manfaat utama dari Mobile learning adalah kemungkinannya untuk meningkatkan produktivitas siswa dengan membuat pengetahuan dan pembelajaran tersedia kapan saja dan di mana saja, memungkinkan peserta didik untuk berpartisipasi dalam kegiatan pembelajaran tanpa batasan tempat dan waktu tradisional. Teknologi seluler mendukung pembelajaran yang dapat diakses dan tersedia secara luas daripada pembelajaran yang digunakan di lingkungan pembelajaran- yang ada.

Mobile learning mendukung kinerja dengan akses mudah ke informasi, yang dapat segera berdampak pada kinerja siswa dalam lingkungan belajar, memfasilitasi pendidikan mereka. Mobile learning mengelola persyaratan pembelajaran yang berbeda, di mana ia secara ideal diarahkan untuk memungkinkan siswa mendapatkan pengetahuan dengan kecepatan mereka sendiri. Mobile learning meningkatkan interaksi dua arah di mana ia mendukung komunikasi langsung antara siswa dan guru mereka, sedemikian rupa untuk mendorong siswa yang pemalu atau ragu untuk berkomunikasi lebih mudah daripada di ruang kelas. Selain itu, guru dari kelompok besar dapat menggunakan interaksi langsung sebagai cara untuk memberikan instruksi khusus kepada semua siswa. Mobile learning juga 
membantu siswa yang menghadapi masalah keuangan, keluarga atau kesehatan dalam bermigrasi ke kelas universitas. Akhirnya, mobile learning adalah motivasi diri, disiplin diri yang mendukung belajar tanpa membuang-buang waktu, belajar di mana saja dan kapan saja.

Media pembelajaran berbasis mobile learning yang dikembangkan valid dan reliabel sehingga layak digunakan. Kemampuan berpikir kritis siswa setelah mengunakan media pembelajaran berbasis mobile learning mengalami peningkatan, dan termasuk dalam kategori peningkatan sedang. Efektivitas media pembelajaran yang digunakan adalah baik dan keterlaksanaan pembelajaran termasuk kategori sangat baik. Sehingga media pembelajaran berbasis mobile learning dapat digunakan sebagai media alternatif dalam pembelajaran untuk membantun meningkatkan kemampuan berpikir kritis siswa.

Mobile learning merupakan sebuah solusi dalam pembelajaran yang mengedepankan aspek kemudahan, kepraktisan serta dapat digunakan dimanapun dan kapanpun.
Pengembangan pembelajaran menggunakan mobile learning pada pembelajaran biologi dapat dilakukan dengan menggunakan berbagai model seperti tutorial, drill and practice, games dan simulasi.

Mobile learning merupakan sebuah solusi dalam pembelajaran yang mengedepankan aspek kemudahan, kepraktisan serta dapat digunakan dimanapun dan kapanpun. Media pembelajaran yang dibuat memiliki beberapa keadaan dan hambatan yang menguntungkan. Media pembelajaran kehebatan dibuat, yang dapat bekerja pada gadget yang bergantung pada Android dan Windows; memperkenalkan materi pemisahan dalam ruang tiga dimensi dengan cara yang menarik dan langsung; menyajikan contoh masalah yang berbeda dengan tingkat kesulitan yang berfluktuasi; presentasi materi dilengkapi dengan gambar dan latihan untuk membantu siswa memahami materi. Media pembelajaran berbasis portable learning yang dibuat sah dan solid dengan tujuan yang pas untuk mereka manfaatkan.Kemampuan berpikir kritis siswa setelah 
mengunakan media pembelajaran berbasis mobile learning mengalami peningkatan, dan termasuk dalam kategori peningkatan sedang. Efektivitas media pembelajaran yang digunakan adalah baik dan keterlaksanaan pembelajaran termasuk kategori sangat baik. Sehingga media pembelajaran berbasis mobile learning dapat digunakan sebagai media alternatif dalam pembelajaran untuk membantun meningkatkan kemampuan berpikir kritis siswa.

Mobile learning merupakan sebuah solusi dalam pembelajaran yang mengedepankan aspek kemudahan, kepraktisan serta dapat digunakan dimanapun dan kapanpun. Pengembangan pembelajaran menggunakan mobile learning pada pembelajaran biologi dapat dilakukan dengan menggunakan berbagai model seperti tutorial, drill and practice, games dan simulasi.

\section{SIMPULAN}

Berdasarkan uraian dalam
hasil telaah maka diambil bahwa
penggunaan mobile learning dalam
pembelajaran siswa sma dapat

digunakan sebagai alat pendukung pembelajaran, media dan sumber belajar dan dapat diterapkan ditingkat siswa sma. Manfaat penggunaan mobile learning dalam pembelajaran adalah agar dapat mempermudah proses belajar mengajar baik yang dikakukan di dalam kelas maupun diluar kelas, menarik perhatian siswa serta dapat membangkitkan semangat dan motivasi dalam pembelajaran sehingga materi yang sedang disampaikan bisa tersampaikan dengan baik dan dapat dipahami oleh siswa, disamping itu manfaat lain dari penggunaan mobile learning adalah dapat menunjang siswa untuk menuju pembelajaran mandiri.

\section{UCAPAN TERIMA KASIH}

Dengan selesainya artikel telaah ini, saya mengucapkan Terima Kasih kepada Tuhan Yang Maha Esa karena atas Karunia dan RahmatNya saya dapat menyelesaikan artikel ini. Tak lupa, saya sampaikan Terima Kasih kepada Bapak Ence Surahman, S.Pd, M.Pd dan Ibu Dra. Susilaningsih, M.Pd. selaku pembimbing mata kuliah Karya Tulis Ilmiah Teknologi Pendidikan yang 
telah membantu, mengajarkan serta membei masukan dan saran terhadap artikel telaah yang telah saya buat dengan tujuan agar saya dapat menyelesaikan artikel telaah ini.

\section{DAFTAR PUSTAKA}

Arif Purnamayana, M. I. (2012).

Rancangan dan pembuatan mobile learning berbasis android. Diakses Pada Http://Repository. Gunadarma. Ac. Id.

Baker, A., Krull, G., \& Mallinson, B. (2005). A proposed theoretical model for m-learning adoption in developing countries. mLearn 2005. In 4th World conference on mLearning: http://www. mlearn. org. za/papers-full. html Fecha de consulta (Vol. 12).

C, L, G, C. (2013). Development of Mobile Learning Using Android Platform. International Journal of Information Technology \& Computer Science ( IJITCS ), Volume 9:

Fatmawati, S. (2015). Pengembangan Mobile Learning Berbasis Android Menggunakan Adobe Flash CS6 Pada Mata Pelajaran Bahasa Inggris Untuk Meningkatkan Hasil Belajar Siswa Kelas X TKJ SMK Hidayah Semarang. Universitas Negeri Semarang.

Inch, E. S. (1989). Critical Thinking and Communication: The Use of Reason in Argument, 6/e.
Pearson Education India.

Kim, D., Rueckert, D., Kim, D.-J., \& Seo, D. (2013). Students' perceptions and experiences of mobile learning. Language Learning \& Technology, 17(3), 52-73.

Komalasari. (2013). Pembelajaran Kontekstual Konsep dan Aplikasi. Bandung: Rafika Aditama.

Kusuma, D. (2016). Pengembangan Mobile Learning Matematika Sebagai Suplemen Pembelajaran Trigonometri Siswa SMA Kelas X. Skripsi. Universitas Kristen Satya Wacana.

MIFTAH RAHMAWATI, A. (2017). Analisis hasil pengembangan media kokami (kotak dan kartu misterius) untuk meningkatkan keterampilan berpikir kritis, aktivitas belajar dan ketuntasan belajar SMP-SMA. Jurnal Pendidikan Ekonomi (JUPE), 5(3).

Nugroho, S. (2014). Pemanfaatan Mobile Learning Game Barisan dan Deret Geometri untuk Meningkatkan Minat dan Hasil Belajar Matematika SMA Kesatrian 1 Semarang. Indonesian Digital Journal of Mathematics and Education, 1(1), 1-7.

Purbasari, R. J., Kahfi, M. S., \& Yunus, M. (2013). Pengembangan aplikasi android sebagai media pembelajaran matematika pada materi dimensi tiga untuk siswa SMA kelas X. Jurnal Online Universitas Negeri Malang, 1(4), 1-10.

$\begin{array}{rrr}\text { Purnama, R. } & \text { B. } & (2017) . \\ \text { Pengembangan } & & \text { Media } \\ \text { Pembelajaran } & \text { Mobile } & \text { Learning }\end{array}$ 
Berbasis Android sebagai Suplemen Pembelajaran Fisika SMA pada Materi Usaha dan Energi.

Setiawati, N., Kartika, I., \& Purwanto, J. (2012). Pengembangan mobile learning (m-learning) berbasis Moodle sebagai daya dukung pembelajaran fisika di SMA. In PROSIDING: Seminar Nasional Fisika dan Pendidikan Fisika (Vol. 3).

Setyadi, D., \& Qohar, A. B. D. (2017). Pengembangan Media Pembelajaran Matematika Berbasis Web pada Materi Barisan dan Deret. Kreano, Jurnal Matematika KreatifInovatif, 8(1), 1-7.

Woodille, G. (2011). Mobile Learning. US: The Mc GrawwHill Companies.

Ghozi, S. (2014). Pengembangan Materi Mobile Learning dalam Pembelajaran Matematika Kelas X SMA Perguruan Cikini Kertas Nusantara Berau. Indonesian

Digital Journal of

Mathematics and Education, 1(1).

Lutfi Isni Badiah, S. Pd., M.Pd. Tanpa

Tahun.

Keefektifan

Pembelajaran Ipa Dengan

Menggunakan Modul Audio

Interaktif Mengenal Bagian

Akar Dan Fungsinya Untuk

Siswa Tunanetra Kelas IV Di

SLB YPAB Surabaya.

Bimbingan dan Konseling

UNIPA Surabaya.
Listiaji, P. (2015). Pengembangan Aplikasi Mobile Learning Sebagai Penunjang Pembelajaran Fisika Pada Materi Hukum Gravitasi Newton Untuk Siswa SMA (Doctoral dissertation, Universitas Negeri Semarang).

Setiawati, N., Kartika, I., \& Purwanto, J. (2012, September). Pengembangan mobile learning (m-learning) berbasis Moodle sebagai daya dukung pembelajaran fisika di SMA. In PROSIDING: Seminar Nasional Fisika dan Pendidikan Fisika (Vol. 3, No. 3).

Ngurahrai, A. H., Farmaryanti, S. D., \& Nurhidayati, N. (2019). Media pembelajaran materi momentum dan impuls berbasis mobile learning untuk meningkatkan kemampuan berpikir kritis siswa. Berkala Ilmiah Pendidikan Fisika,7(1), 6270.

Rusli, A. (2013). Aplikasi Mobile Learning Ilmu Biologi untuk siswa Kelas II Program IPA Tingkat Sekolah Menengah 
Atas Berbasis Android (Studi

Kasus SMA Pasundan 2

Bandung) (Doctoral

dissertation, Universitas

Komputer Indonesia).

Wahyudi, I. (2017). Pengembangan

program pembelajaran fisika

sma berbasis e-learning

dengan schoology. Jurnal

Ilmiah Pendidikan Fisika Al-

BiRuNi, 6(2), 187-199.

Junaedi, E. (2013). Pengaruh Modul

Elektronik Berbasis Mobile

Learning terhadap Peingkatan

Hasil Belajar Siswa pada Mata

Pelajaran Teknologi

Informasi dan Komunikasi:

Kuasi Eksperimen Terhadap

Siswa Kelas $X \quad$ SMA

Laboratorium Percontohan

UPI, Bandung (Doctoral

dissertation, Universitas

Pendidikan Indonesia).

Aripin, I. (2018). Konsep dan

Aplikasi Mobile Learning dalam

Pembelajaran Biologi. BIO

EDUCATIO:(The Journal of

Science and Biology

Education), 3(1).

Triyanti, M., Harmoko, H., \& Lestari,

N. (2018). Efektivitas Model
Pembelajaran Course Review

Horay terhadap Hasil Belajar

Biologi dan Motivasi Siswa

Kelas $\mathrm{X} \quad$ SMA

NegeriJayaloka. BIOEDUKA

SI, 9(2), 99-108.

Pradana, D. A., \& Mahfud, M.

(2017). DESAIN DAN

PENGEMBANGAN MEDIA

PEMBELAJARAN MOBILE

LEARNING BERBASIS

SEJARAH LOKAL MATA

PELAJARAN SEJARAH

UNTUK KELAS $\quad \mathrm{X}$

SMA NEGERI 1

GAMBIRAN. Progressif:

Jurnal Ilmu Pengetahuan

dan Teknologi, 14(3), 13-17.

Meilana, J. R. (2017). Pengembangan

Modul Mobile Learning Berbasis

Android Pada Materi Fluida Statis.

Riyadi, A. (2017). Aplikasi Media

Pembelajaran Mobile

Learning Berbasis ndroid

Materi Sistem Ekskresi

Manusia untuk siswa kelas XI

SMA/MA. JURNAL ILMIAH

KOMPUTER GRAFIS, 10(1).

Setyadi, D. (2017). Pengembangan mobile learning berbasis android sebagai sarana 
berlatih mengerjakan soal matematika. Satya

Widya, 33(2), 87-92.

Musahrain, M., Suryani, N., \& Suharno, S. (2017, March). Pengaplikasian Mobile Learning Sebagai Media dalam Pembelajaran. In Prosiding Seminar Nasional Teknologi Pendidikan.

Kusuma, D. 2016. Pengembangan Mobile Learning Matematika Sebagai Suplemen Pembelajaran

Trigonometri Siswa SMA Kelas X. Skripsi. Universitas Kristen Satya Wacana.

Maulana, L. 2017. Pengembangan Media Pembelajaran Berbasis Mobile Learning dengan Platform Android Materi Keselamatan Kesehatan Kerja dan Lingkungan Hidup (K3LH) Pada Program Studi Ketenagalistrikan untuk Siswa Sekolah Menengah Kejuruan. Program Studi Pendidikan Teknik Mekatronika 7(2): 188-207

Kartikawati, S., \& Pratama, H. (2017). Pengaruh penggunaan whatsapp messenger sebagai mobile learning terintegrasi metode group investigation terhadap kemampuan berpikir kritis. JUPITER (Jurnal Pendidikan Teknik Elektro), 2(2), 33-38.

Mardiana, N. (2017). Peningkatan physics hots melalui mobile learning (mobile learning to improve physics hots). PASCAL (Journal of Physics and Science Learning), 1(2).

Ngurahrai, A. H., Fatmaryanti, S. D., \& Nurhidayati, N. (2018). Studi pendahuluan pengembangan media pembelajaran berbasis mobile learning untuk meningkatkan kemampuan berpikir kritis peserta didik. In Proceeding of The URECOL (pp. 219-222)

Setiawati, N., Kartika, I., \& Purwanto, J. (2012). Pengembangan moble learning (m-learning) berbasis moodle sebagai daya dukung pembelajran fisika di SMA. Jurnal Prosiding Seminar Nasional Fisika Dan Pendidikan Fisika UNS, 3(3)

Darmawan, D. (2016). Mobile Learning Sebuah Aplikasi 
Teknologi Pembelajaran.

Jakarta : Rajawali Press

Sarrab, Mohamed, Laila Elgamel, \&

Hamza Aldabbas. (2012).

Mobile Learning

Learning) and Educational

Environments. International

Journal of Distributed and

Parallel System, 3(4): p. 35

Scepanovic, S. dkk. (2015). Game

Based Mobile Learning-

Application Development and

Evaluation. The Sixth

International Conference on e-

Learning.

Rahayu, M.S.I. 2017. Pengembangan

Media Pembelajaran Berbasis

Mobile Learning Pada

Platform Android Sebagai

Sumber Belajar Untuk

Meningkatkan Kemandirian

Belajar Dan Hasil Belajar

Fisika Peserta Didik Kelas X.

Skripsi. Yogyakarta: FMIPA

UNY.

Irawan, R., \& Sukarna, I. M.

Pengembangan

Media

Pembelajaran Kimia

Sma/Ma Berbasisandroid

Dengan Mobile Learning

Pada Materi Konfigurasi
Elektron Dan Tabel Periodik Unsur.

Yektyastuti, R., \& Ikhsan, J. (2016).

Pengembangan media

pembelajaran berbasis

android pada materi

kelarutan untuk meningkatkan performa akademik siswa SMA. Jurnal Inovasi

Pendidikan IPA, 2(1), 88-99.

Surahman, E., \& Surjono, H. D. (2017). Pengembangan adaptive mobile learning pada mata pelajaran biologi SMA sebagai upaya mendukung proses blended learning. Jurnal Inovasi Teknologi Pendidikan, 4(1), 2637. 